R. Sergio Balches Arenas Uniwersytet Jagiellonski, Kraków sergio.balches_arenas@uj.edu.pl

\title{
Reflexiones sobre la influencia de las TIC en el sistema educativo actual
}

\section{Abstract: \\ Some Thoughts on the Impact of ICT in Education}

The advent of ICT in society has been an unprecedented event as regards the adoption of new ways of conceiving work, education, leisure, etc., in our daily lives. The so-called "digital natives" play a key role in the process versus the group developed in the era before ICT - "digital immigrants". This article offers a reflection on the state of education in general, and on the current influence of ICT on the design of new models of education, different to those supported by traditional education systems.

Keywords: ICT, digital native, digital immigrant, digital literacy, prosumer, educational system.

\section{Streszczenie:}

\section{Kilka refleksji na temat roli TIK w procesie edukacji}

Technologie informacyjno-komunikacyjne (TIK), które z impetem wdarły się w życie współczesnych społeczeństw, przyniosły ze sobą szereg bezprecedensowych zmian i zrewolucjonizowały zarówno dotychczasowy sposób pojmowania pracy, nauki czy rozrywki, jak również wiele nawyków naszego życia codziennego. Kluczowymi postaciami zachodzącego procesu 
przeobrażeń są tzw. „cyfrowi tubylcy”, w odróżnieniu od osób, które dorastały w epoce poprzedzającej inwazję TIK, określanych mianem „,cyfrowych imigrantów". Niniejszy artykuł jest próbą refleksji nad sytuacją edukacji w ogóle, lecz przede wszystkim jego autor stara się odpowiedzieć na pytanie, w jaki sposób eksplozja TIK warunkuje w chwili obecnej powstawanie nowych form i sposobów nauczania, odmiennych od modeli wypracowanych przez tradycyjne systemy edukacji.

Słowa kluczowe: technologie informacyjno-komunikacyjne (TIK), ,cyfrowi tubylcy”, ,cyfrowi imigranci”, alfabetyzacja cyfrowa, prosument, system edukacyjny.

\section{Introducción}

Desde la aparición de las TIC (Tecnologías de la Información y la Comunicación) hasta el momento actual, se han venido produciendo numerosos cambios en distintos ámbitos de la sociedad, la educación, el trabajo, la cultura, etc. Las TIC, de hecho, no sólo han supuesto una auténtica revolución para el ser humano, sino que, además, han provocado que éste cambie sus patrones de pensamiento y de actuación, lo cual indica el grado de importancia de las mismas en el desarrollo del mundo actual.

Existen precursores, como Marshall McLuhan, cuando se refiere al concepto de "aldea global", citado por Javier Echeverría [1994: 184]: "McLuhan parece explicar los grandes cambios en las formas de organización social por medio de la irrupción de diversas tecnologías o media: la rueda, la escritura, [...]", y el propio Echeverría ahonda en ello señalando que, en general, son los media los que propugnan el avance y los cambios sociales. Tanto McLuhan como Echeverría demuestran una amplia visión, aún cuando las TIC no habían tenido en el momento de realizar estas aseveraciones un amplio calado en la sociedad. Serán con posterioridad Terceiro y Matías [2001: 45] los que incidan en el aspecto de globalización y de irrupción de lo digital en la sociedad en los siguientes términos: 
En la globalización resultante de la conjunción de todas esas esferas de la vida social, la nueva totalidad del digitalismo pasa a ser más que la suma o agregación de las partes que interactúan en ese resultado. El digitalismo es el nuevo escenario u horizonte socioeconómico, que está dotado de un nuevo orden y de un nuevo sistema de relaciones humanas, las propias de la sociedad de la información y del conocimiento.

Así pues, el mundo digital pasa a formar parte de la vida cotidiana de las personas, afectando múltiples áreas de influencia y creando no sólo un nuevo sistema de relaciones humanas, como señalan Terceiro y Matías, sino también una nueva forma de afrontar la gestión de esa información y de ese conocimiento a los que estos autores hacen referencia.

La pretensión de nuestro artículo consistirá en realizar una reflexión acerca de la capacidad de los sistemas educativos de adaptarse a la introducción de las TIC, de los déficits existentes y de cómo ha venido cambiando la conciencia de la sociedad en cuanto a la implementación de dichas TIC en diversos ámbitos de la vida cotidiana. También pretende ofrecer un somero perfil de los actuales ciudadanos del mundo digital, frente a aquellos que pertenecen a la era predigital, especialmente en cuanto a sus actitudes, concepción del trabajo y gestión de la información y del conocimiento. Sin duda surgirán cuestiones que pueden ofrecer puntos de vista controvertidos para los lectores de este trabajo, aunque estamos seguros de que lo verdaderamente importante es abrir un amplio debate social que impulse un auténtico avance en el propio sistema educativo, el cual ha de permitir una profundización en cuanto a la aplicación de las TIC en el ámbito escolar. Además, consideramos que éste se ha de llevar a cabo desde una perspectiva acorde a las nuevas formas de concebir el mundo por parte de las nuevas generaciones que están llegando a las aulas. 


\section{Educación predigital frente a educación digital}

No cabe duda en cuanto al hecho de que la educación en sí misma es un complejo mundo que encierra múltiples matices y que posee numerosas vías de estudio e investigación: la didáctica general, las didácticas específicas, la metodología de la enseñanza, la pedagogía, la psicología de la educación, la psicopedagogía, la teoría de la educación..., y así, un largo etcétera de ramas del saber científico que se ocupan de este fenómeno. Ahora bien, nuestra pretensión es centrarnos concretamente en un aspecto concreto: la presencia de las TIC en el mundo de la enseñanza.

En este sentido, hemos de comenzar con una cuestión que, a prio$r i$, constituye uno de los ejes en los que se habrá de desenvolver el presente artículo y que se centra en la evolución del sistema educativo en función a la aparición de tecnologías que, en cada época, merced a su novedad y a sus posibilidades de aplicación en la docencia, han modificado teorías pedagógicas, metodológicas y didácticas para favorecer una mejor adaptación de las mismas a la enseñanza. Un claro ejemplo al respecto de esta situación se puede encontrar en el caso concreto de la enseñanza de lenguas extranjeras, dado que es una de las ramas didácticas que mayor sensibilidad ha mostrado en los últimos decenios a adoptar elementos tecnológicos para incluirlos como parte integrante del proceso de enseñanza-aprendizaje. Para ser exactos, podemos ver un inicio consciente de esta situación en la introducción de la tecnología en el programa del ejército norteamericano ASTP (Army Specialized Training Program), destinado a enseñar idiomas a los militares que iban a entrar en campaña durante la II Guerra Mundial y que se puso en marcha en 1943. Tal como señala Sánchez [1997: 154], las cintas magnetofónicas y el laboratorio de idiomas, iban a adquirir una especial relevancia, constituyendo una parte destacada de lo que después se conocería como "método audiooral". Obviamente, resulta una importante revolución para la enseñanza de lenguas pasar de un período premagnetofónico a un periodo magnetofónico, dado que, si seguimos la estela de los métodos de en- 
señanza posteriores, veremos que tanto dichas cintas magnetofónicas, como los discos y, posteriormente, las casetes, cintas de vídeo, los CD y los DVD, llegarán a convertirse en una herramienta de trabajo indispensable en el aula y fuera de ella.

Lo que en su día supuso una revolución, tal como hemos dicho, se fue convirtiendo poco a poco en una cotidianeidad que llegó a ser global y universal en la era predigital, no sólo en la enseñanza de idiomas, sino también en otras disciplinas académicas. El siguiente hito vendría marcado por la irrupción de las TIC en el ámbito de la educación: si bien tímidamente en un principio, paulatinamente se fueron introduciendo cada vez en más ámbitos, hasta llegar al momento actual, en el cual dichas TIC se han convertido en un elemento cercano al mundo educativo, pero no porque el propio sistema las haya adaptado a sus fines y necesidades, sino porque forman parte intrínseca de la vida cotidiana de los discentes.

En este aspecto, hay que realizar, desde nuestro punto de vista, una crítica al propio sistema, pues, según lo señalado por Pérez [2005: 170]:

[...] la fractura del uso de los distintos tipos de lenguajes está servida desde el instante en que el desarrollo social y tecnológico de la comunicación ha apostado por un lenguaje más de tipo visual, audiovisual, mientras que las instituciones educativas siguen tratando de mantener una centralidad uniforme en el uso de un solo formato basado en la escritura.

No sólo eso, sino que además, consideramos que los sistemas educativos oficiales han seguido manteniendo, en la mayoría de los casos, currículos centrados en la demostración por parte del alumno de la consecución de los objetivos académicos a través de la obtención de una calificación, merced a la realización del correspondiente examen o de la prueba de turno que planteen dichos currículos. Dicho de otra manera, el sistema entra en una obsolescencia que lo aleja del ámbito digital, al que, desde nuestro punto de vista, sólo accede puntualmente para utilizar las TIC como elemento sustitutivo de los medios tradicionales de enseñanza, con lo cual, si bien se cambia la for- 
ma, no se altera ni el contenido ni el trasfondo del tipo de enseñanza propiciado por dicho sistema educativo. Por ello, consideramos que la presencia de las TIC en el ámbito educativo se traduce generalmente en el hecho de disponer de ordenadores, tabletas u otros medios de procesamiento informático cuya única finalidad consiste en utilizarlos, bien como una extensión de los materiales didácticos tradicionales, bien como un complemento a la docencia tradicional o incluso como una herramienta que pueda dar pie a una incipiente alfabetización digital, en lugar de usarlos como medios de pleno aprendizaje de competencias educativas, sociales, digitales, comunicativas, etc.

Hemos de coincidir con la línea manifestada a este respecto por Richard Gerver, el cual propugna profundos cambios en las aulas que vengan a aplicar de lleno la utilización en múltiples dimensiones de las TIC en el ámbito escolar, dado que señala en una entrevista realizada en TVE [en línea] ${ }^{1}$, que "está claro que se está utilizando una metodología decimonónica para la generación escolar del siglo XXI", lo cual ha provocado una ruptura con aquellos aspectos comunes existentes en las generaciones escolares anteriores, y además, de una forma radical, dado que -como señalábamos al principio- la difusión y uso de las TIC se ha universalizado hasta el punto de que hoy día tienen una presencia activa en, prácticamente, todos los aspectos relacionados con el ser humano.

Pensamos que se hace necesaria una mayor apertura hacia las TIC por parte de los sistemas educativos y una mayor implicación de éstos en la aplicación de las mismas en las aulas, puesto que nos enfrentamos, como podremos apreciar más adelante, a una nueva generación de personas que en la actualidad conviven diariamente con el mundo digital, que desde el inicio de sus vidas ha sido una parte integrante de su desarrollo individual desde múltiples dimensiones, y precisamente por ello el ámbito educativo presenta un desfase o brecha, no sólo en cuanto a la forma de aplicar los contenidos curriculares en las aulas, sino también en cuanto a la forma de rentabilizar los procesos cog-

${ }^{1}$ Entrevista aparecida en el programa Redes, titulado "Crear hoy las escuelas de mañana”, emitido por Televisión Española el 31.07.2011. 
nitivos de estos individuos que se desenvuelven en un plano distinto al de aquellos individuos de las generaciones anteriores, cuestión que será tratada en un capítulo posterior de este trabajo.

Así, en el ámbito educativo se han de propugnar cambios que deben tender a ofrecer un nuevo modelo de enseñanza, basado en las aptitudes, capacidades y competencias de aquellas personas para las que las TIC han dejado de ser lo que hoy en día se sigue denominando por parte de algunos sectores poblacionales (y también educativos) "nuevas tecnologías", dado que, de hecho, ya dejaron hace tiempo de ser "nuevas" al entrar a formar parte de la vida cotidiana de la sociedad contemporánea. Precisamente, siguiendo lo expuesto por Granger [2005: 18] podemos apreciar que ya han empezado a producirse algunos cambios en el ámbito educativo, los cuales plasma este autor en el siguiente cuadro:

\begin{tabular}{|c|c|c|}
\hline & Sistema tradicional & Sistema basado en las TIC \\
\hline Profesor & $\begin{array}{l}\text { - Dirige el proceso } \\
\text { educativo }\end{array}$ & $\begin{array}{l}\text { Prima la coordinación } \\
\text { y orientación educativa }\end{array}$ \\
\hline Alumno & $\begin{array}{l}\text { - Receptor pasivo } \\
\text { - Formación reglada }\end{array}$ & $\begin{array}{l}\text { - Autoaprendizaje } \\
\text { - La formación tiene en } \\
\text { cuenta sus preferencias }\end{array}$ \\
\hline Contenidos & - Áreas básicas & $\begin{array}{l}\text { - Desarrollo de procesos } \\
\text { mentales } \\
\text { - Formación en TIC }\end{array}$ \\
\hline Soporte & $\begin{array}{l}\text { - Papel impreso } \\
\text { - Audio (casete o radio) }\end{array}$ & $\begin{array}{l}\text { - Ordenador multimedia } \\
\text { - Internet } \\
\text { - Televisión } \\
\text { - DVD }\end{array}$ \\
\hline Escenario & - Aulas & $\begin{array}{l}\text { - Escuelas expandidas } \\
\text { - (aulas y hogar) }\end{array}$ \\
\hline Método & - Enseñanza presencial & - Formación continua \\
\hline
\end{tabular}

Tabla 1. Comparación de la enseñanza tradicional y la enseñanza basada en las TIC, según Granger 
No es de extrañar, pues, que según Prensky [2001: 4], se haga preciso una profunda modificación, tanto en la metodología como en el contenido por parte de los docentes, dado que en uno y otro caso, existe una brecha propiciada por el sistema educativo en cuanto a lo que éste es capaz de ofrecer a los estudiantes en la actualidad y lo que dichos estudiantes son capaces de hacer por sí mismos, es decir, qué competencias, en cuanto a acciones y a conocimientos poseen.

Todo esto se debe a la aparición de los llamados "nativos digitales", término acuñado por Prensky [2001: 1], el cual gozó de mayor fortuna que los términos $\mathrm{N}$-gen (generación $\mathrm{N}$-por Internet), o D-gen (generación $\mathrm{D}$ - de digital), y que describe a aquellas personas cuyo estilo de vida y conocimiento del mundo se tamiza a través de las TIC, dado que las conciben como un hecho próximo y cotidiano. Dichas personas poseen unas características particulares en cuanto a la forma de trabajar, procesar la información, comunicarse, $y$, en definitiva, en cuanto a todo lo relacionado con las actividades de la vida cotidiana, incluyendo también el aprendizaje.

\section{Alfabetización digital, nativos e inmigrantes digitales}

Si nos hubieran preguntado en nuestra época escolar cuestiones teóricas acerca de las TIC, hubiéramos demostrado ser prácticamente profanos en esta temática; cuánto más si, en lugar de simplemente interrogarnos sobre ello, nos hubieran colocado delante de un moderno portátil para realizar las más elementales tareas que hoy son cotidianas en la web 2.0, incluso para un niño, pues tal como señala Piscitelli [2006: 182], en la actualidad existe una sobreexposición temprana de la infancia a las TIC:

[En Estados Unidos] la generación de chicos actuales, nacidos entre mediados de los noventa y principios del año 2000 se están introduciendo a/en los medios [...] a través del intermediario digital y no a través del papel o de la imprenta. 
De ello se infiere que nos hallamos en una situación en la que la generación escolar que pisaba las aulas antes del decenio 90 del siglo XX era "analfabeta digital", en el sentido de que, tal como señala Miranda [en línea], no cumplía con los tres requisitos básicos para ser considerada "alfabeta digital", esto es: "1. El manejo de un computador y sus periféricos. 2. Manejo de softwares esenciales. 3. Conocimiento informático". Ello se confirma a través de lo señalado por Valero y Mompin [en línea] para aquellas personas que se hallaban escolarizadas (en el caso de España) en los decenios 80 y 90 del siglo $\mathrm{XX}$, tanto en EGB como en BUP y FP²:

En el Plan Electrónico e Informático Nacional (PEIN) de 1984 había un capítulo dedicado a la enseñanza. [...] Este Programa se denominó ATENEA, y el ministerio invirtió 4777 millones de pesetas para el período $1985-89$, repartiéndose de la forma siguiente: $63,7 \%$ para equipos; 19,6\% para cursos de formación del profesorado; $7 \%$ reuniones; $6,7 \%$ gastos generales y $3 \%$ material didáctico. A lo largo de los 5 años que duró el proyecto se dotó a 1843 centros (1155 de EGB, 414 de BUP, y 274 de FP) con un total de 9215 microcomputadores; se impartieron 685 cursos para la formación de 5530 profesores y la especialización de otros 1288, celebrándose 34844 seminarios y mesas redondas. Esto demuestra el interés que suscitó Atenea en el medio escolar.

Nos encontramos, de esta manera, con un intento por parte de la administración educativa española de subsanar la carencia de conocimientos digitales durante el decenio 80 y principios del decenio 90 del siglo XX en el ámbito escolar. Dicho intento se reproduciría por parte de otras administraciones educativas nacionales en sus respectivas áreas geográficas, lo cual, obviamente, dio pie a la introducción

${ }^{2}$ Según la nomenclatura establecida por la Ley Orgánica 1/1990, de 3 de octubre, de Ordenación General del Sistema Educativo, la antigua EGB (Educación General Básica), equivale a la actual Educación Primaria y parte de la Educación Secundaria Obligatoria y el antiguo BUP (Bachillerato Unificado Polivalente), equivale a otra parte de la Educación Secundaria Obligatoria y al actual Bachillerato. Por su parte, FP (Formación Profesional) sigue manteniendo su equivalencia con la estructura organizativa actual. 
de la informática a nivel de usuario como materia en los currículos escolares, de tal manera que, al menos, pudiera empezar a darse una incipiente alfabetización digital en las aulas.

Tenemos que hacer especial hincapié en que, además, los escolares nacidos en fechas posteriores a las señaladas, de repente se encontraron inmersos desde el principio en entornos propiciadores de la alfabetización digital, merced al desarrollo de herramientas tecnológicas y de programas específicos que fomentaban la interactividad de estos sujetos con el propio medio digital en el que se iniciaban en edades muy tempranas en el ámbito del hogar. La alfabetización digital cobrará así una importancia relevante, no sólo en el ámbito educativo, sino también en otras esferas de la vida, aunque ello conlleva por otro lado un aspecto negativo: la aparición de la denominada por Prensky [2001: 1] "brecha digital", pues según Cabero y Llorente [2008: 12]:

La alfabetización tecnológica es un prerrequisito de ciudadanía en la sociedad del conocimiento y de desarrollo profesional en la economía del conocimiento. Su contrapartida, la brecha digital se concibe hoy día como una barrera al desarrollo personal y social, y como una divisoria social de la misma importancia que la economía. Las reflexiones que se siguen intentan mantener este doble enfoque: humanista, de desarrollo de las capacidades esenciales de la persona, y pragmático, de respuesta a las demandas de las nuevas economías.

Esta brecha digital, de hecho, constituía -y constituye hoy día-, un elemento diferenciador entre las generaciones nacidas antes del decenio 90 del siglo XX y las nacidas con posterioridad, dado que estas últimas poseerán unas características específicas que las convierte en un nuevo tipo de ciudadanos, con unos intereses y una forma de interactuación con la tecnología totalmente distinta, pues, según señala Prensky [2001: 1], estas generaciones

[...] representan las primeras generaciones que han crecido con esta nueva tecnología. Han pasado toda su vida rodeados de, y usando, ordenadores, videojuegos, reproductores digitales de música, videocámaras, móviles, y todos los demás juguetes y herramientas de la era digital. Hoy en día la media de los graduados universitarios ha pasado menos 
de 5.000 horas de su vida leyendo, pero más de 10.000 horas jugando con videojuegos (por no hablar de las 20.000 horas viendo la televisión). Los juegos de ordenador, el correo electrónico, Internet, los teléfonos móviles y la mensajería instantánea son parte integrante de sus vidas,

lo cual supone, sin lugar a dudas, un claro reflejo de una nueva realidad que se había asentado con gran celeridad en la sociedad de finales del siglo XX y principios del siglo XXI. De este planteamiento desarrollado por Prensky surgió el concepto de "nativo digital", que engloba a la generación que "habla" y domina el lenguaje de los ordenadores, frente al concepto de "inmigrante digital", que engloba a las generaciones anteriores que han tenido que adaptarse a ese lenguaje a posteriori de su surgimiento.

Los nativos digitales cuentan con una ventaja frente a los inmigrantes digitales, que consiste en el hecho de haberse visto involucrados, no sólo en un proceso de adquisición de lengua materna, sino también en un proceso de adquisición de competencias digitales, dado que comienza a percibir el mundo desde una nueva óptica, en la que la iconicidad, la interactividad y la multimodalidad adquieren una mayor preponderancia que la verbalización o que las destrezas manuales (y por destrezas manuales, nos referimos, por ejemplo, a los tediosos cuadernos de caligrafía que utilizaban los docentes en nuestro proceso de alfabetización y adquisición de destrezas lecto-escritoras), dado que, según indica Dans [en línea], existen contenidos en la actualidad que se acercan al mundo del niño, que lo ponen en contacto con los medios digitales y que, además, le permiten desarrollar sus habilidades cognitivas. Esto, sin duda, sitúa a los miembros de la nueva generación digital en un plano de actuación y de conocimiento del mundo totalmente distinto al de las generaciones pretéritas.

Así pues, nos encontramos con una nueva forma de procesar la realidad y de gestionar el aprendizaje que se contrapone al modelo tradicional, aún imperante en numerosos sistemas educativos, y que se centra en diversos aspectos, tales como la gestión de la información y del conocimiento, la forma de trabajar, el estilo de aprendizaje, etc., puesto que el nativo digital y el inmigrante digital poseen unas 
características diferenciadoras que detalla Prensky [2001: 2-3] en su artículo, y que nosotros resumiremos en el siguiente cuadro:

\section{Características de los nativos digitales}

- Reciben información en forma rápida.

- Les gustan los procesos y multitareas paralelos.

- Prefieren gráficos antes que el texto.

- Defienden los accesos al azar (desde hipertextos).

- Funcionan mejor cuando trabajan en red.

- Prosperan con satisfacción inmediata y bajo recompensas frecuentes.

- Eligen jugar en "serio" en vez de trabajar.
Características de los inmigrantes digitales

- Estructuras mentales moldeadas por los procesos paso a paso

- Proceso de trabajo instruccional o de resolución de un problema cada vez.

- Actuación basada en el análisis deductivo.

- Aprendizaje basado en el enlace con conocimientos preadquiridos.

\section{Algunas marcas de los inmigrantes digitales}

- Imprimir un documento digital para leerlo o corregirlo.

- Llamar a una persona para avisar o confirmar que se le ha enviado un SMS o un correo electrónico.

- Leer el manual de instrucciones de cualquier equipo antes de usarlo.

Tabla 2. Diferencias entre los nativos digitales y los inmigrantes digitales, según Prensky

A raíz de lo señalado por Prensky, consideramos necesario resaltar el hecho de que los sistemas educativos tienen que prestar atención cada vez más a estas características propias de los nativos digitales, debido a que existe un hecho absolutamente innegable: en la actualidad, quienes toman las decisiones, los que gestionan los sistemas educativos, muchos de los que imparten clases, etc., son inmigrantes di- 
gitales. Esa obviedad no sería tan superficial si no fuera por el hecho de que son ellos los que tienen que comprender a los nativos digitales desde múltiples perspectivas: sus motivaciones, sus necesidades, sus esquemas de pensamiento, etc. (todo lo cual, como hemos podido ver, resulta ser diferente entre inmigrantes y nativos digitales). No obstante, parece que intentar que un inmigrante digital comprenda a un nativo digital y piense como él es casi lo mismo, a veces, que intentar explicar una pieza musical a una persona con minusvalía auditiva.

\section{De la alfabetización digital a la prosumición}

Una cuestión problemática en la actualidad, tanto para nativos digitales como para inmigrantes digitales, consiste en gestionar la información y el conocimiento, lo cual viene provocado por la ingente cantidad de información y datos existentes al alcance de todo el mundo que disponga de herramientas digitales y de conexión a Internet. No es un hecho baladí plantear esta situación, pues si bien la capacidad de usar un ordenador, sus programas y sus periféricos están en el ámbito de la alfabetización digital, se produce un salto, tanto cuantitativo como cualitativo, cuando además se es capaz de interactuar con las herramientas TIC, pasando de la alfabetización digital a una competencia digital que, al igual que la competencia comunicativa, puede gradarse en cuanto al nivel de domino de dichas herramientas y al grado de interacción que el usuario posee con respecto a las mismas.

Hay que señalar que esa competencia digital provoca que el usuario de las TIC deje de ser un mero receptor pasivo de la información, para convertirse él mismo en productor activo de nueva información o productor de una información previamente recibida en un formato reelaborado. Así pues, pasa a ser un prosumidor $^{3}$, transformando las

${ }^{3}$ Basándonos en Islas [2007: 73], "la palabra prosumidor -en inglés, prosumer-, es un acrónimo que procede de la fusión de dos palabras: "producer" 
herramientas digitales, y más concretamente las existentes en la web 2.0, en entornos de trabajo en red, en los cuales la colaboratividad, la interacción y la cultura de la remezcla son algunos de sus aspectos más representativos y característicos. Eso implica que cualquier persona con capacidad de acceso a la red y con capacidad de uso de las herramientas web 2.0 es un prosumidor que desempeña un papel activo en la gestión de la información y del conocimiento. A este respecto, Islas [2007: 76] indica que:

[...] debemos reconocer a los prosumidores como los actores comunicativos de la sociedad de la ubicuidad. El papel de los prosumidores resultará definitivo en las siguientes remediaciones que experimentarán en Internet como el conjunto de dispositivos que formen parte de los ambientes comunicativos que deriven del desarrollo de las comunicaciones digitales móviles. [...], disponiendo de un extenso repertorio de recursos multimedia, emprenden determinadas acciones comunicativas, como expresar sentimientos, difundir información, compartir conocimientos $[\ldots]$.

De hecho, el prosumidor, al basarse en una cultura de remezcla, tal como hemos señalado con anterioridad, contribuye a una redifusión de la información que, a veces, llega a ser en exceso reiterativa, con lo que se ha de tener en cuenta que hay que atender a algunos elementos relacionados con el proceso global de gestión de la información, los cuales, según el informe realizado por la OCDE sobre habilidades y competencias del siglo XXI para los aprendices [2010: 7], consisten en:

[...] habilidades de investigación y resolución de problemas, que conllevan en algún punto definición, búsqueda, evaluación, selección, organización, análisis e interpretación de la información.

(productor) y "consumer" (consumidor). El concepto fue anticipado por Marshall Mcluhan y Barrington Nevitt, quienes en el libro Take Today (1972), afirmaron que la tecnología permitiría al consumidor asumir simultáneamente los roles de productor y consumidor de contenidos. Mcluhan infería que en la edad posteléctrica los actores comunicativos resentirían profundas transformaciones resultantes de la complejidad inherente a nuevos ambientes comunicativos". 
Específicamente, las habilidades de selección y de evaluación nos conducen a un hecho de suma importancia en la actualidad por parte del usuario de las TIC: poder desarrollar la capacidad de discriminar la información, lo cual, tal como señala dicho informe de la OCDE [2010: 7], nos obliga a recurrir al concepto de "alfabetización informacional", por la cual "un estudiante entiende primero, y luego define claramente la información en base a una pregunta o tarea determinada." Por otro lado, también la información que se reestructura y que proviene de la remezcla por parte del prosumidor puede llevar a producir el desarrollo de nuevas ideas autóctonas, lo cual, según la OCDE [2010: 8], "puede transformar y desarrollar la información de muchas maneras para entender mejor, comunicar con más efectividad a los demás y desarrollar las interpretaciones o ideas de uno mismo a base de una cuestión determinada".

Así pues, podemos ver que los avances que se producen en cuanto a la aparición de nuevas competencias en torno a las TIC son cada vez más complejos, a la par que ingentes, en el sentido de que es necesario desarrollar por parte de los usuarios digitales nuevos elementos competenciales que giren en torno a una adecuada gestión del conocimiento y de la información. La pregunta que nos surge al respecto de esta situación es la siguiente: ¿está realmente preparado el sistema educativo actual para afrontar el reto de facilitar a las nuevas generaciones de jóvenes el acceso activo a esas competencias?

Tenemos que volver al informe ya citado de la OCDE [2010: 3 ] para ver qué recomendaciones se hacen a los gobiernos a este respecto:

$[\ldots]$ los gobiernos deberían hacer un esfuerzo para identificar y conceptualizar correctamente el conjunto de habilidades y competencias requeridas según los estándares educativos que cada estudiante debe ser capaz de alcanzar al final de la educación obligatoria [...].

No obstante, todo este proceso corre el riesgo de ser irrelevante para las escuelas a no ser que este conjunto de habilidades y destrezas se convierta en el núcleo duro de lo que los profesores y las escuelas deberían tomar en consideración. Esto sólo es posible a través de su incorporación en el sistema educativo nacional, a su vez, reforzado y evaluado por las autoridades. 
En relación a lo señalado, resulta que si no se produce una implicación activa por parte de las autoridades educativas y también por parte de los intervinientes en el proceso de enseñanza-aprendizaje, difícilmente se podrá dar una respuesta adecuada a unas personas que, como hemos visto, participan de lo que podemos denominar una "deslocalización educativa", dado que han superado el mito de la escuela como el espacio único y posible del aprendizaje, y han desplazado dicho aprendizaje a diversos entornos multifocales, en los que la escuela, sólo es uno de esos entornos. Desde nuestro punto de vista, la desmitificación del aula como templo del aprendizaje es algo que debe ser asumido por los sistemas educativos, pues de otra manera, la brecha existente entre los sistemas educativos y los propios usuarios de dichos sistemas educativos, está condenada a ir ampliándose cada vez más debido a que puede llegar un momento en el que la educación, tal como la conocemos hoy día, se colapse debido a su obsolescencia con respecto a los avances de las TIC. Ello produciría dos mundos distintos que hablarían dos lenguajes absolutamente irreconciliables e ininteligibles entre sí: por un lado, el mundo de los profesores, anclados en los modelos tradicionales y en las soluciones escolares que ofrecen los sistemas educativos oficiales, y por otro lado el mundo de los alumnos, que conciben el aprendizaje como un intercambio constante de información, que rehúyen de lo memorístico dado que tienen la información disponible en cada momento gracias a la tecnología y que no son capaces ni de concebir ni de asumir las obligaciones y las constricciones que emanan del sistema educativo para ser considerados "buenos estudiantes".

\section{Conclusiones}

En este artículo hemos pretendido mostrar una realidad que cada vez se ha vuelto más global y universal: el uso constante de las TIC en diferentes ámbitos de la vida, entre ellos, el de la educación. Sería 
un panorama ideal, si no fuera porque aparece un foco de resistencia en cuanto a la interpretación de qué hacer con esas TIC en el ámbito educativo desde el punto de vista de los sistemas educativos estatales, que paulatinamente intentan ofrecer soluciones, pero en una cantidad insuficiente y con una predisposición bastante laxa.

Esto choca con una actitud, una forma de vida y una forma de organizar el pensamiento que se ha ido extendiendo cada vez más: la de los nativos digitales. No es que sean -permítasenos la ironía"seres mutantes" o un "nuevo producto" de la raza humana. Nada de eso. Se trata de personas que han tenido una exposición activa desde que prácticamente nacieron a las tecnologías de la información y la comunicación, las cuales han marcado profundamente su forma de percibir la realidad, de aproximarse a la información, de gestionarla, de afrontar los procesos comunicativos de forma distinta a como lo hacían sus antecesores, etc., todo ello unido a unas destrezas y competencias propiamente tecnológicas, sin las cuales no tendrían acceso a las herramientas informacionales.

Así pues, los sistemas educativos, dirigidos y gestionados por miembros de las generaciones que se denominan "inmigrantes digitales" (y a veces ni siquiera eso), chocan frontalmente con los nativos digitales, los cuales cuentan con una ventaja formidable frente a aquellos que tuvimos que asistir al colegio en épocas pretéritas: la escuela ya no es el único referente de aprendizaje y formación. Las TIC constituyen el punto focal a través del cual se deslocaliza la información y se particulariza para cada usuario de las TIC al mismo tiempo: es lo que Islas [2007: 77] llamará "glocalización"4. Y es que la tecnología permite a los nuevos alumnos tener una visión global

${ }^{4}$ Acrónimo que proviene de la unión de las palabras inglesas globalization (globalización) y localization (localización), cuya significación, desde un punto de vista económico, "se refiere a la persona, grupo, división, unidad, organización o comunidad que está dispuesta y es capaz de «pensar globalmente y actuar localmente». El concepto implica que la empresa se adapte a las peculiaridades de cada entorno, diferenciando sus producciones en función de las demandas locales" (http://es.wikipedia.org/wiki/Glocalizaci\%C3\%B3n). 
del mundo, de la sociedad, de los valores, etc., sin necesidad de moverse de su entorno más cercano.

Entonces, si ello es así, ¿cuál será el futuro de los profesores? ¿Seguirán haciendo falta o podrán ser sustituidos por programas instruccionales? Obviamente, la respuesta es meridianamente clara: los profesores hacen falta hoy día y seguirán haciendo falta en el futuro. Lo que realmente debemos preguntarnos es si los actuales currículos académicos son los adecuados para formar al profesorado del futuro, dado que en unos 50 años ya no estará en activo ningún inmigrante digital, por lo que el problema de una brecha, tanto de conceptualización como de conocimiento, existe aquí y ahora. Los nativos digitales ya están en las aulas universitarias, y siguen recibiendo una enseñanza propia de inmigrantes digitales, lo cual produce un impacto entre la forma de aprender de unos y la forma de enseñar de otros. Hay que hacer una clara apuesta desde los sistemas educativos oficiales para cambiar esa situación e intentar aproximar a la enseñanza tradicional todo lo bueno que tienen que ofrecernos las TIC, y ello tiene que apoyarse en el profesorado: hay que apoyar una nueva orientación pedagógica para los futuros docentes que englobe las competencias y habilidades en el uso de las TIC, sus posibilidades de explotación didáctica $\mathrm{y}$, por supuesto, que pueda convertir a los docentes en unos orientadores activos que faciliten a los estudiantes el desarrollo de sus propias competencias y habilidades en su interrelación con las TIC, respetando su forma de trabajar, su forma de concebir la realidad y sus esquemas cognitivos. Según nuestro punto de vista, esta debe ser la orientación que, a corto plazo y siguiendo las recomendaciones de la OCDE, deben adoptar dichos sistemas educativos nacionales. 


\section{Bibliografía}

AA.VV., Wikipedia, [on-line] http://es.wikipedia.org/ - 6.06.2012.

ADELL, J., "La navegación intertextual en el World-Wide Web: implicaciones para el diseño de materiales educativos", [on-line] http://nti.uji.es/ docs/nti/edutec95.html - 2.05.2012.

BARTOLOMÉ, A., GRANÉ, M. [et al.] (2007), "La web audiovisual", Tecnología y Comunicación Educativas, 21, 45, Instituto Latinoamericano de la Comunicación Educativa, Ciudad de México, pp. 20-41.

B.O.E., Ley Orgánica 1/1990, de 3 de octubre, de Ordenación General del Sistema Educativo, [on-line] http://www.boe.es/buscar/doc.php?id=BOE-A-1990-24172 - 5.06.2012.

BOHÓRQUEZ, E. (2008), "El blog como recurso educativo", EDUTEC-e, 26, [on-line] http://edutec.rediris.es/Revelec2/revelec26/articulos_n26_ PDF/Edutec-E_Bohorquez_n26-\%203.pdf - 6.05.2012.

CABERO, J. (2004), "Las TICs como elementos para la flexibilización de los espacios educativos: retos y preocupaciones", Comunicación y pedagogía, 194, Centro de Comunicación y Pedagogía, Barcelona, pp. 13-19.

CABERO, J., LLORENTE, M.C. (2008), "La alfabetización digital de los alumnos. Competencias digitales para el siglo XXI", Revista Portuguesa de Pedagogía, 42, 2, [on-line] http://tecnologiaedu.us.es/cuestionario/bibliovir/jca26.pdf - 16.05.2012.

CASTAÑEDA, L.J. (2009), "Las universidades apostando por las TIC: modelos y paradojas de cambio institucional", EDUTEC-e, 28, [on-line] http://edutec.rediris.es/Revelec2/revelec28/articulos_n28_pdf/Edutec-E_Castaneda_n28.pdf - 29.05.2012.

CASTRO, V., "Nora Aznar: videojuegos y webquest, formas de integrar las TIC y el aprendizaje colaborativo en la escuela", [on-line] http://portal.educ.ar/noticias/entrevistas/nora-aznar-videojuegos-y-webqu-1.php -4.05 .2012 .

DANS, E., "Una nueva generación”, [on-line] http://www.todovaacambiar. com/capitulo-8-una-nueva-generacion - 4.05.2012.

ECHEVERRÍA, J. (1994), Telépolis, Ediciones Destino, Barcelona.

GERVER, R. (2010), Creating Tomorrow's Schools Today. Education - Our Childrens - Their Future, Continuum, London.

GERVER, R., "Crear hoy las escuelas de mañana", entrevista en el programa Redes de TVE, [on-line] http://www.rtve.es/television/20101213/crear-hoy-escuelas-manana/385896.shtml - 7.05.2012. 
GRANGER, J.R. (2005), "La transformación de los sistemas educativos", en: Edukared (ed.), Enseñar a aprender. Internet en la educación. Nuevos paradigmas y aplicaciones educativas, vol. I, Fundación Telefónica, Madrid, pp. 3-48.

ISLAS, O. (2007), "La sociedad de la ubicuidad, los prosumidores y un modelo de comunicación para comprender la complejidad de las comunicaciones digitales", Revista Latinoamericana de Ciencias de la Comunicación, 7, [on-line] http://www.alaic.net/portal/revista/r7/art_04. pdf - 21.05.2012.

MIRANDA, M., "Qué es el analfabetismo digital", [on-line] http://monica-miranda.suite101.net/analfabetismo-digital-a18821 - 7.05.2012.

OCDE (2010), Habilidades y competencias del siglo XXI para los aprendices del nuevo milenio en los países de la OCDE, [on-line] http:// recursostic.educacion.es/blogs/europa/media/blogs/europa/informes/ habilidades_y_competencias_siglo21_OCDE.pdf - 3.06.2012.

PÉREZ, R. (2005), “Alfabetización en la comunicación mediática: la narrativa digital", Comunicar, 25, Grupo Comunicar, Huelva, pp. 167$-175$.

PISCITELLI, A. (2006), "Nativos e inmigrantes digitales: ¿brecha generacional, brecha cognitiva, o las dos juntas y más aún?", Revista Mexicana de Investigación Educativa, 11, 28, [on-line] http://redalyc.uaemex.mx/ redalyc/pdf/140/14002809.pdf - 8.05.2012.

PISCITELLI, A. (2009), Nativos digitales. Dieta cognitiva, inteligencia colectiva y arquitectura de la participación, Santillana, Buenos Aires.

PRENSKY, M. (2001), "Digital Natives, Digital Immigrants. Part 1", On the Horizon, 9, 5, [on-line] http://www.marcprensky.com/writing/prensky $\% 20 \% 20$ digital $\% 20$ natives, $\% 20$ digital $\% 20$ immigrants $\% 20-\% 20$ part1.pdf-4.05.2012.

PRENSKY, M. (2010), Teaching Digital Natives, Corwin Press, Thousand Oaks.

RICHARDS, J.C., RODGERS, T.S. (2009), Enfoques y métodos en la enseñanza de idiomas, Edinumen, Madrid.

SÁNCHEZ, A. (1997), Los métodos en la enseñanza de idiomas. Evolución histórica y análisis didáctico, SGEL, Madrid.

SOTOMAYOR, G. (2010), "Las redes sociales como entorno de aprendizaje colaborativo mediado para segundas lenguas (L2)", EDUTEC-e, 34, [on-line] http://edutec.rediris.es/Revelec2/Revelec34/pdf/Edutec-e_n34_Sotomayor.pdf - 15.05.2012. 
TERCEIRO, J.B., MATÍAS, G. (2001), Digitalismo. El nuevo horizonte sociocultural, Taurus, Madrid.

VALDÉS, M.C., ARMAS, N. [et al.] (2008), "Una herramienta TIC estratégica para crecimiento profesional en la sociedad de conocimiento: la formación transversal curricular de competencias comunicativas", EDUTEC-e, 26, [on-line] http://edutec.rediris.es/Revelec2/revelec26/ articulos_n26_PDF/Edutec-E_Valdes_n26.pdf - 9.05.2012.

VALERO, M., MOMPIN, J., "La informática en España", [on-line] http:// www.mompin.es/HistoriadelainformaticaenEspana9.htm - 24.05.2012.

VILLALBA, C., "Las nuevas brechas del siglo XXI: las digitales", [on-line] http://cristian-villalba.suite101.net/las-nuevas-brechas-del-siglo-xxi-las-digitales-a53185 - 8.05.2012. 